\title{
Effect of decreased water oxygen content on common carp fry with Dactylogyrus vastator (Monogenea) infection of varying severity
}

\author{
K. Molnár \\ Veterinary Medical Research Institute, Hungarian Academy of Sciences, PO Box 18, H-1581 Budapest, Hungary
}

\begin{abstract}
In 5 experiments, common carp fry Cyprinus carpio with Dactylogyrus vastator infection of varying severity, as well as parasite-free fry, were placed into an environment of decreasing oxygen content. The correlation between the time of death and helminth infestation of the gills was studied. The experiments demonstrated that in a medium of decreased oxygen content the carp with the heaviest helminth infection died first while helminth-free controls survived longest.
\end{abstract}

KEY WORDS: Dactylogyrus vastator Monogenea $\cdot$ Common carp - Oxygen deprivation

\section{INTRODUCTION}

The effects of parasitic infections and their role in the mortality of animals are difficult to assess. According to parasitology manuals, e.g. that of Kotlán \& Kobulej (1972), heavy infection with certain parasites may lead to the animal's death even in the absence of other factors, while other parasite species do not necessarily cause the host's death and, even when colonizing the host in large numbers, induce clinically apparent dis ease only if certain predisposing factors are present. The majority of fish parasites belong to this latter group. However, Dactylogyrus vastator, described by Wunder (1929), can act in both these ways. According to Paperna (1964) and Bauer et al. (1981), rapid infection of small fish by large numbers of larvae very often causes mortality in common carp fry. At the same time, Schaeperclaus (1954) suggested that fish can tolerate even infections of very high intensity; however, their survival chances are negatively affected by adverse environmental factors and poor feeding conditions. Low water oxygen content is one of the most important adverse environmental factors. For instance, Overstreet (1993) identified low oxygen content of water as the most important stress factor contributing to the massive fish mortality caused by Amyloodinium ocellatum. Under natural conditions, assessment of the pathogenicity of individual parasites and of the role they play in fish diseases is rendered difficult by the fact that adverse environmental conditions as stress factors facilitate the simultaneous development of bacterial, viral and fungal diseases that manifest themselves in much more pronounced clinical signs Because of these facts, the experimental approach seems to be the only method suitable for studying, in a reliable manner, the effect exerted by environmental factors on the development of parasitoses.

Using Dactylogyrus vastator as a model, in these experiments I studied to what extent common carp fry with different levels of infection could tolerate one of the most common stress factors, i.e. oxygen depletion of the water. Differences in tolerance between fish infected by parasites and uninfected common carp were also studied.

\section{MATERIALS AND METHODS}

For the experiments, spawn from a single mother fish Cyprinus carpio were hatched in the laboratory and reared in tap water, under sterile conditions, free from parasitic and bacterial infections. The fish were fed Artemia salina; they were 1 mo old and measured 17 to $23 \mathrm{~mm}$ at the time of the experiment. 
For infection, Dactylogyrus vastator infected common carp fry derived from a farm pond were used. They were freed from ectoparasitic protozoa by $2 \times$ $24 \mathrm{~h}$ exposure to $0.1 \%$ malachite green solution. These fish were removed from the aquarium, and upon the appearance of oncomiracidia swimming in the water ( 3 to 4 d) parasite-free fish were placed into it for different periods. The degree of infection was assessed by sacrificing some fish and counting the oncomiracidia that had lost their cilia and were present on the skin. and gills of the fish. Efforts were made to produce fish of varying degrees of infection by placing the fish into aquaria containing oncomiracidia for varying times. In this way fish infected by a few dozen or by 100 to 200 worms were obtained. Exceptionally, after short exposures, some fish remained uninfected. The fry infected by the above procedure were included in the experiment, using some uninfected fish as controls. The experiments were performed after the helminths had reached maturity (i.e. when their hooks and anchors had developed and the first eggs appeared), but no new infection was produced by the eggs laid.

The experimental fish were placed into a $4 \mathrm{l}$ aquarium completely filled with water and having no fresh air supply. The infection-free fish and fish of varying degrees of infection were kept in the same aquarium space in all experiments except in the first experiment in which they were separated by a net within the aquarium. The fish were removed from the aquarium as they died. In some experiments (Expts 1, 3 and 4) the longest-surviving 2 or 3 fish were killed by decapitation. On the death of each fish, the time of death and the temperature of water were recorded, and water oxygen content was measured with an Aquacheck-3 (Radelkis) apparatus. In all but one experiment, temperature was also set at a certain constant level. The dead fish were dissected under a stereomicroscope and the number of worms clinging to their gills were counted. By the order of their death, fish were divided into groups of 10 to 12 . The specimens infected by the lowest and the highest number of worms, as well as the mean worm burden, were indicated for each group. The statistical significance of differences observed between the groups was studied by Student's $t$-test on the basis of the mean worm burden. The number of uninfected specimens in the different groups is also shown in the tables.

\section{RESULTS}

By the bathing and infection procedure applied, we managed to produce common carp fry stocks infected exclusively by Dactylogyrus vastator. Depending on the length of time for which the fish were kept in the water containing oncomiracidia, heavily and less heavily infected groups of fish could be produced.

It was a general tendency in the 5 experiments that fish with a heavier worm burden died sooner than those infected by fewer worms. However, the order of death showed substantial variations. Based on the time of their death the uninfected fish were consistently among the last ones to die; however, occasionally some fish specimens showing a low degree of infection exhibited higher tolerance than the uninfected ones.

In Expt 1, 24 fish which later turned out to be infected by 50 to 160 worms, and 12 control fish, were placed into a closed aquarium. The severely affected fish died in $10 \mathrm{~min}$ to $3 \mathrm{~h} 5 \mathrm{~min}$ after having been placed in the aquarium (Table 1). At the time of death of the last fish, the dissolved oxygen concentration in the water was $1.3 \mathrm{mg} \mathrm{l}^{-1}$ As at the time of death of the last infected fish specimens all control fish were still alive, they were killed mechanically.

Expt 2 (Table 2) included 40 infected and 20 parasite-free carp. Eight fish showing mechanical injuries were removed from the aquarium without examination. The fish died between $30 \mathrm{~min}$ and $6 \mathrm{~h} 40 \mathrm{~min}$ after having been placed into the aquarium. During that time the oxygen content of the water declined from 1.6 to $0.9 \mathrm{mg} \mathrm{l}^{-1}$ For statistical evaluation the fish were divided into 2 groups of 11 and 3 groups of 10 fish post mortem, by taking into consideration the order of their death. The number of worms found on the infected fish ranged between 8 and 160. The mean worm burden of the 11 fish that died first was 98.8 ,

Table 1 Expt 1. Correlation between Dactylogyrus vastator infection and oxygen deficiency tolerance of common carp fry Cyprinus carpio

\begin{tabular}{|lccc|}
\hline & Group 1 & Group 2 & Group 3 \\
\hline No. of fish grouped by order of death & $1-12$ & $13-24$ & $25-36$ \\
Time to death (h:min) & $0: 10-2: 00$ & $2: 00-3: 05$ & $3: 05-\mathrm{killed}$ \\
Water oxi'gen content at time of death & $3.6-1.6$ & $1.6-1.3$ & 1.3 \\
Water temperature at time of death $\left({ }^{\circ} \mathrm{C}\right)$ & 26 & 26 & 26 \\
Worm burden: mean & 113.16 & 96.66 & 0 \\
$\quad($ range) & $(60-150)$ & $(50-160)$ & \\
\hline
\end{tabular}


Table 2. Expt 2. Correlation between Dactylogyrus vastator infection and oxygen deficiency tolerance of common carp fry Cyprinus carpio. U: no. of uninfected specimens

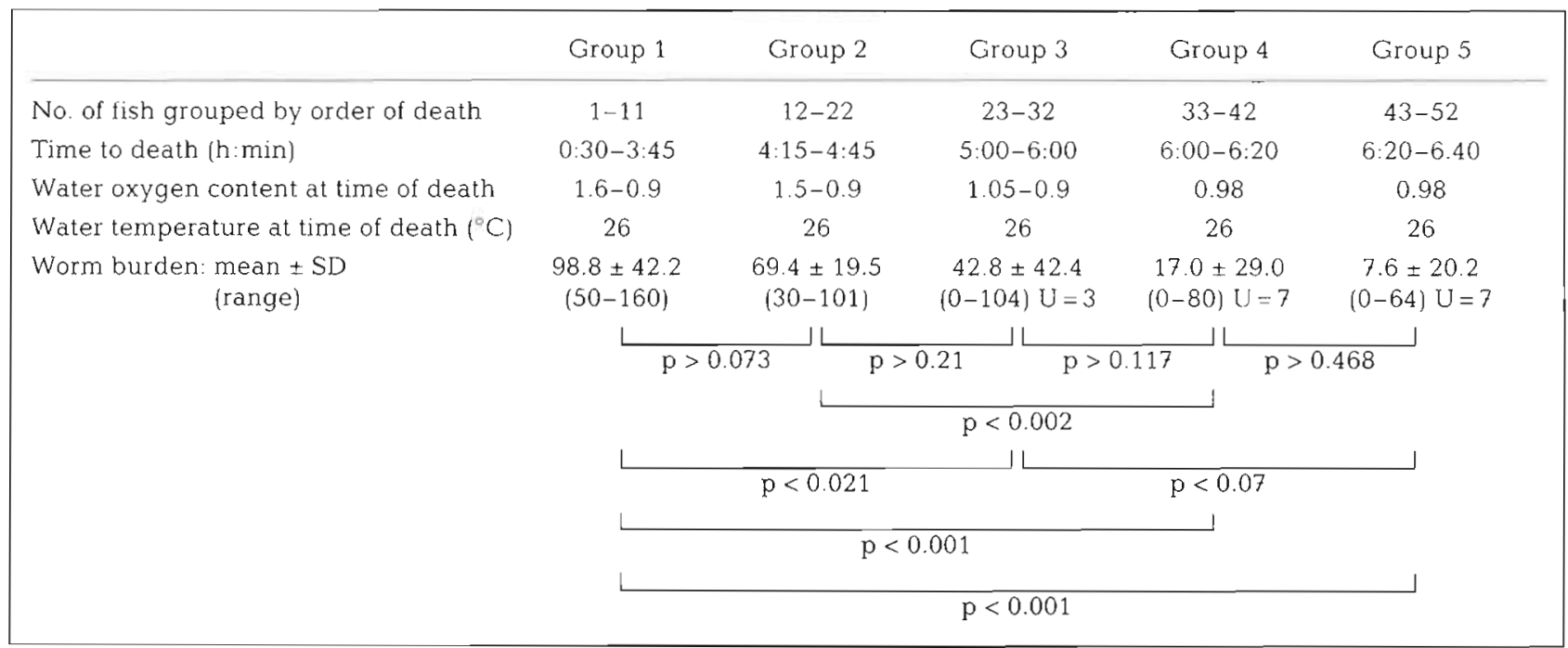

while that of fish that died subsequently was 69.4 , $42.8,17$ and 7.6 , respectively. All of the 3 groups having a lower worm burden contained specimens that were not infected.

Expt 3 (Table 3 ) included 40 infected and 10 control fish. The fish died between $10 \mathrm{~min}$ and $5 \mathrm{~h} 50 \mathrm{~min}$, while the oxygen content of the water dropped from 1.9 to $0.98 \mathrm{mg} \mathrm{l}^{-1}$. The fish were divided into groups of 10 which showed the following mean worm burdens: $183.4,142.3,46.5,30.7$, and 3.3. The last group included a fish specimen infected by 33 worms, while in the group before last an uninfected fish also died (as fish no. 35).
Expt 4 (Table 4) also involved 40 infected and 10 control common carp. Forty-three of the fish died between $10 \mathrm{~min}$ and $4 \mathrm{~h} 40 \mathrm{~min}$, while the remaining 7 were killed. By the time of death of the last fish, water oxygen content had decreased from 1.1 to $0.75 \mathrm{mg} \mathrm{l}^{-1}$. The fish divided into groups of 10 harboured 90.1, 63.7, 50.2, 11.9 and 2.4 parasites, respectively. The last group contained 7 uninfected specimens while the one before last had 4 uninfected carp. Probably the fish exposed to infection also contained an uninfected specimen.

Expt 5 (Table 5) included 48 infected and 10 uninfected fish. The first fish died at $3 \mathrm{~h} 30 \mathrm{~min}$, when the

Table 3. Expt 3. Correlation between Dactylogyrus vastator infection and oxygen deficiency tolerance of common carp fry Cyprinus carpio. U: no. of uninfected specimens

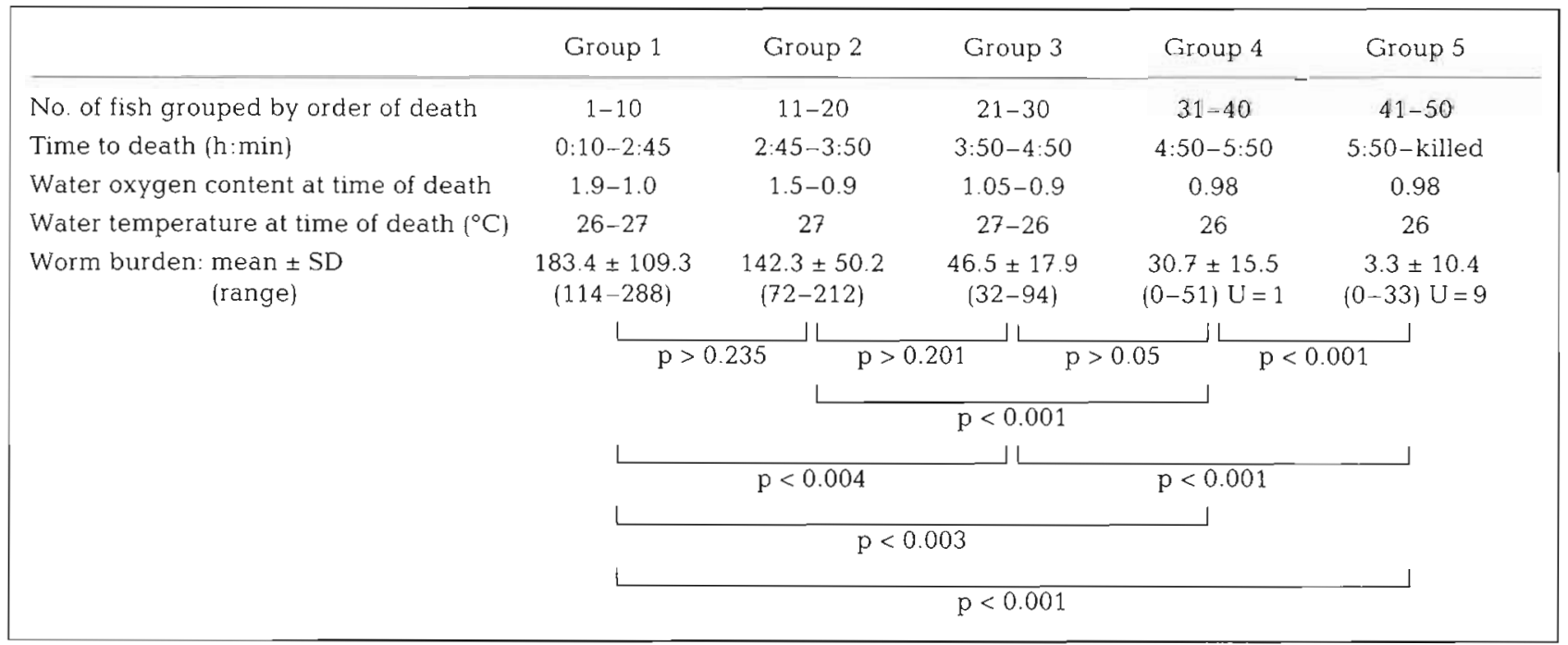


Table 4. Expt 4. Correlation between Dactylogyrus vastator infection and oxygen deficiency tolerance of common carp fry Cyprinus carplo. U: no. of uninfected specimens

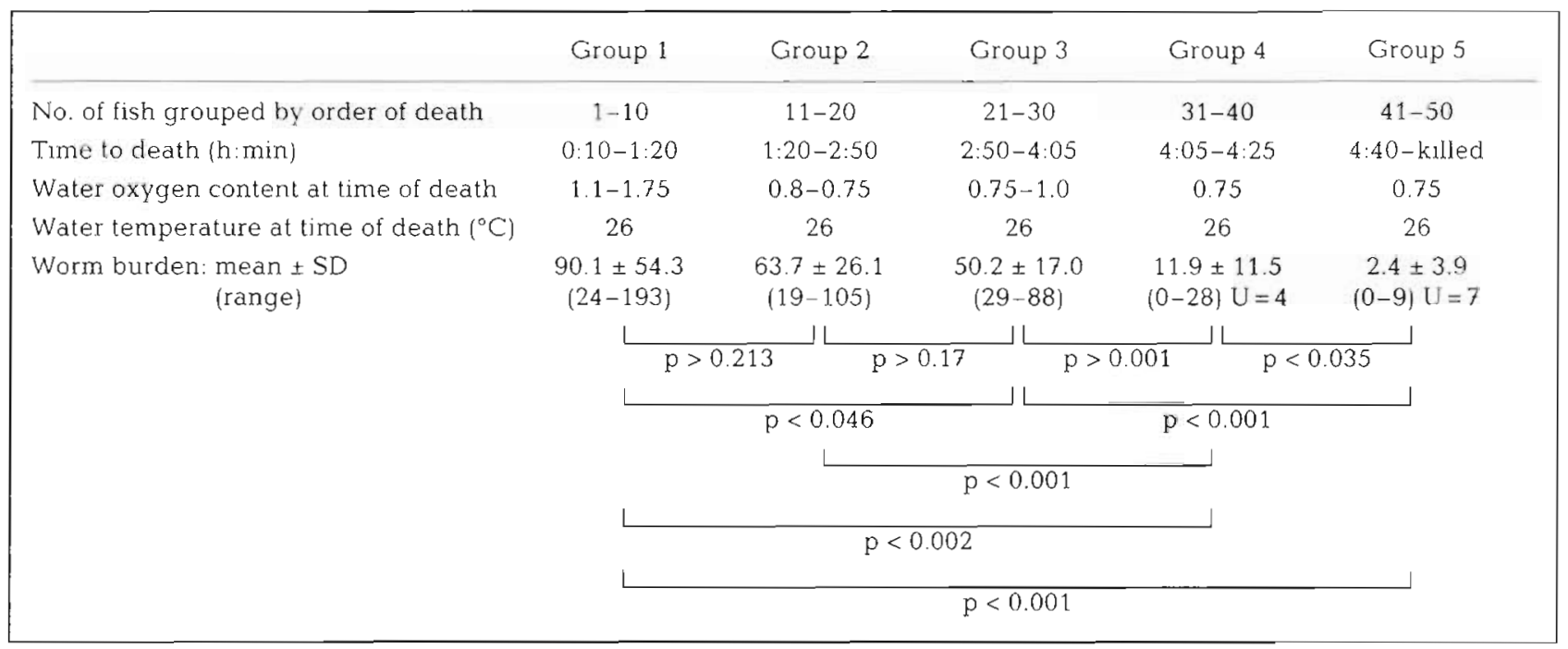

oxygen content of the water was $0.9 \mathrm{mg} \mathrm{l}^{-1}$. The last fish died at $9 \mathrm{~h}$, when water oxygen content was $0.7 \mathrm{mg}$ $\mathrm{I}^{-1}$. The mean worm burdens of the 5 groups of 10 fish and of the sixth group comprising the 8 remaining fish specimens were $186.5,118.4,37.3,37.6,4.5$ and 8.2 respectively. The last group contained 4 while the one before last included 6 uninfected fish.

Based upon the observed worm burden, significant differences rarely occurred between neighbouring groups of 10 to 12 fish categorized according to the order of death. At the same time, between groups showing larger differences in the time of death there was always a statistically significant difference in the mean worm burden (Tables 2 to 5 ).

\section{DISCUSSION}

Parasitic infection inevitably exerts an adverse effect on the host. The extent of that effect may range from extremely detrimental to negligible. Scott \& Dobson (1989), who studied the role of parasites in regulating

Table 5. Expt 5. Correlation between Dactylogyrus vastator infection and oxygen deficiency tolerance of common carp fry Cyprinus carpio. U: no of uninfected specimens

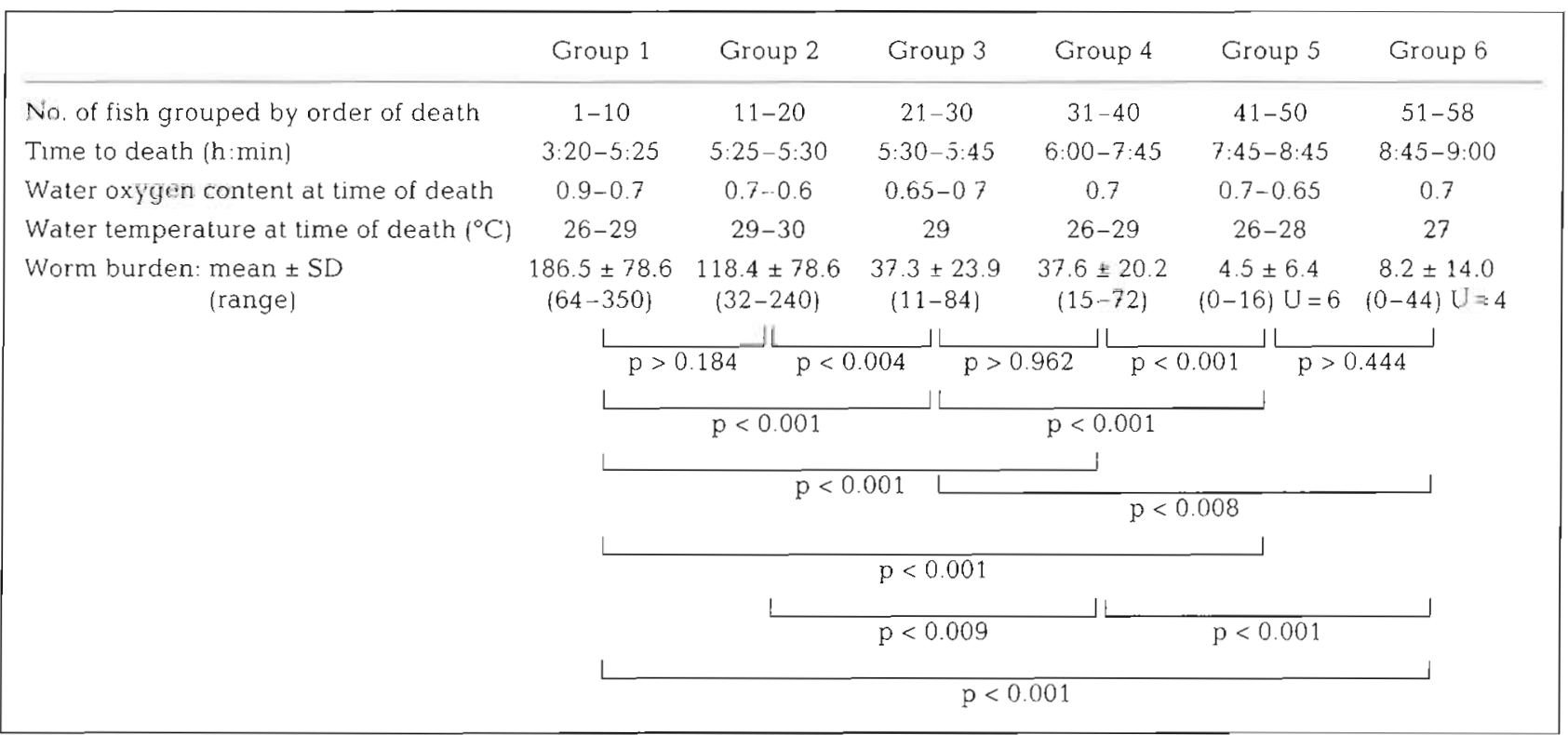


host abundance, concluded that even minor infections had an impact on the abundance of the host species. While, however, they compared only 2 factors (the degree of parasitic infection and host abundance), in the experiments reported here a third factor, i.e. the effect of oxygen-deficient environment as a stress factor on the host-parasite balance, was studied.

Studies by Wunder (1929), Layman (1951), Paperna (1964) and Kollmann (1972) have clearly shown that Dactylogyrus vastator is an important pathogenic parasite which may cause deaths even by itself, depending on the worm burden and the size of the host fish. Paperna (1964) reported a substantial reduction in the respiratory surface of the gills as a result of infection. According to Uspenskaya (1961), such fish take up half as much oxygen. At the same time, reports by fish farmers and our own observations suggest that common carp can occasionally survive severe dactylogyrosis. Mortality is usually associated with the body condition of the fish, the presence of adverse environmental factors, and the occurrence of concomitant infections.

The results of the present experiments demonstrate that certain factors impairing the natural resistance of fish (in our model the decreasing oxygen content of the water) may aggravate a sublethal infection into a lethal one. Experiments in which we managed to establish infections of widely varying severity (with worm burdens ranging from a few to several hundred worms) unambiguously proved that the fish with the heaviest worm burden always died first, while less severely infected carp could tolerate the oxygen-deficient environment for a much longer time. There was a significant difference in tolerance between common carp having a massive worm burden and those infected by a few helminths only. The difference in the tolerance of oxygen deficiency was especially well visible between the heavily infected and the uninfected fish. At the same time, there is clearly an individual variation in the resistance of fish: thus, some of the carp infected by a small number of worms (Expts 3 to 5) occasionally proved to be more resistant than some uninfected individuals. Depending on the methodology of removing the dead fish and on the distribution of deaths, replenishment with oxygen varied in the different experiments. This fact would seemingly render the obtained data non-comparable. However, these experiments were not aimed at studying the correlation between oxygen level and the degree of parasitic infection. An oxygen-deficient environment was used merely as one of the stress factors to which fish are exposed, in order to study how fish with varying degrees of infection react to stress caused by a given environmental factor.
In the case studied in this work, a direct correlation existed between the presence of the respiratory pathogen Dactylogyrus vastator and death due to oxygen deprivation. However, the observations made by Overstreet (1993) on Amyloodinium and the experiments conducted by Molnár (1993) on eels with the swimbladder nematode Anguillicola crassus call attention to the fact that the connection between a given parasitic infection and oxygen deficiency is not always a direct one. Low oxygen level as a stress factor may aggravate even a parasitosis that has no direct influence on respiration into a disease of fatal outcome. Fish farmers are familiar with the little understood mass mortality due to oxygen deficiency, which occurs in certain ponds at dawn on August days and usually involves only a certain part of the stock. It is very likely that in such cases only fish having intact gills and free from parasites as well as from clinically unapparent diseases can survive the transient oxygen deficiency.

Acknowledgements. The author thanks Ms Emese Papp for skilful technical assistance. In addition thanks are expressed to A. Gubányi for statistical evaluation of data. The work was supported by the National Research Fund (OTKA), contract no. 1985.

\section{LITERATURE CITED}

Bauer, O. N., Mussehus, V. A., Strelkov, J. A. (1981). Diseases of pond fishes. Publishing House Legkhaya i Pishtsevaya Promishlennost, Moscow (in Russian)

Kollmann, A. (1972). Dactylogyrus vastator Nybelin, 1924 (Trematoda, Monogenoidea) als Krankheitserreger auf den Kiemen des Karpfens (Cyprinus carpio L.). Z. wiss. Zool. (Leipzig) 185: 1-54

Kotlán, S., Kobulej, T (1972). Parasitology. Mezógazdasági Kiadó, Budapest (in Hungarian)

Layman, E. M. (1951). The influence of water temperature on the reproduction of Dactylogyrus vastator. Trudy mosk. Tekhnol. Inst. ryb. Proml. Khoz. 4: 190-196

Molnár, K. (1993). Effect of decreased oxygen content on eels Anguilla anguilla infected by Anguillicola crassus (Nematoda: Dracunculoidea). Acta Vet. Hung. 41. 349-360

Overstreet, R. M. (1993). Parasitic diseases of fishes and their relationship with toxicants and other environmental factors. In: Couch, J. A., Fournie, J. W. (eds.) Pathobiology of marine and estuarine organisms. CRC Press, Boca Raton, p. $111-156$

Paperna, I. (1964). Host reaction on infestation of carp with Dactylogyrus vastator Nybelin, 1924 (Monogenea). Bamidgeh 16: 129-141

Schaeperclaus, W. (1954). Fischkrankheiten. AkademieVerlag, Berlin

Scott, M. E., Dobson, A. (1989). The role of parasites in regulating host abundance. Parasitol. Today 5: 176-183

Uspenskaya, A. A. (1961). Effect of Dactylogyrus vastator Nybelin, 1924 to the organism of the common carp. Zool. Zh. $10: 7-12$

Wunder, W. (1929). Die Dactylogyrus Krankheit der Karpfenbrut, ihre Ursache und ihre Bekämpfung. Z. Fisch. 27. $511-545$

Manuscript first received: March 22, 1994

Revised version accepted: August 4, 1994 